\title{
Evolutionary rates of secondary sexual and non-sexual characters among birds
}

\author{
JOSÉ JAVIER CUERVO ${ }^{1 *}$ and ANDERS PAPE MØLLER ${ }^{2}$ \\ ${ }^{1}$ Estación Experimental de Zonas Áridas, Consejo Superior de Investigaciones Cientificas, Calle \\ General Segúra 1, E-04001 Almeria, Spain; ${ }^{2}$ Laboratoire d'Ecologie, CNRS URA 258, Université \\ Pierre et Marie Curie, Bât. A, 7'ème étage, 7 quai St. Bernard, F-75252 Paris Cedex 5, France \\ (*author for correspondence, fax: +34950 277 100; e-mail: jcuervo@eeza.csic.es)
}

Received 26 July 1999; accepted 28 December 1999

Co-ordinating editor: P. Harvey

\begin{abstract}
The rate of evolutionary morphological change in secondary sexual characters among species has traditionally been assumed to exceed that for non-sexual characters, giving rise to a larger degree of divergence. We used a large data set of independent evolutionary events of exaggerated secondary sexual feather characters across all birds to test whether that was the case. Comparative analyses revealed that secondary sexual tail feather characters diverged more than wing feathers in females, and we also found that secondary sexual head feather characters diverged more than tarsi in males, when only including intra-order comparisons in the analyses. These results are in the predicted direction, with secondary sexual characters diverging more than ordinary morphological traits, partially supporting the general impression that secondary sexual characters are more variable among species than ordinary morphological characters. However, the degree of divergence among secondary sexual characters was generally not much larger than that among ordinary characters. Some non-significant differences in divergence between secondary sexual characters and ordinary characters could be explained by the cost-reducing function of ordinary morphological traits. There was no evidence of significant differences in divergence between sexes for secondary sexual characters, maybe because of genetic correlations in morphology between the sexes. However, male tarsi diverged more than female tarsi, and sexual selection might play a role in this difference in divergence.
\end{abstract}

Key words: feathers, rate of evolution, sexual selection, speciation

\section{Introduction}

Sexual selection has produced an amazing diversity of extravagance such as the horns of beetles, the train of the peacock Pavo cristatus and the antlers of deer (Darwin, 1871). Such secondary sexual characters have evolved and are maintained by sexual selection due to the effects of female choice and/or male-male competition. There is considerable variation in secondary sexual characters within species, much more than for comparable characters that do not play a role in sexual selection (e.g., Alatalo et al., 1988; Pomiankowski and Møller, 1995; Cuervo and Møller, 1999). There is also considerable 
variation in secondary sexual characters among species, as already noted by Darwin (1871), and later by a number of different scientists who realized the importance of sexual selection for speciation and species divergence (e.g., Kaneshiro, 1980; Lande, 1981; Thornhill and Alcock, 1983; West-Eberhard, 1983, 1984; Kaneshiro and Boake, 1987; Ryan and Rand, 1993; Rice and Hostert, 1993; Lambert and Spencer, 1995; Møller and Cuervo, 1998; Price, 1998).

This apparently larger degree of divergence in secondary sexual characters among species, as compared to that of other phenotypic traits, has been attributed to the fact that the expression of secondary sexual characters may play an important role in mate recognition and other aspects of pre-mating reproductive isolation. Reproductive isolation appears as a consequence of disruptive selection on phenotypic traits. The evolution of mate recognition traits, which prevents or limits the flow of genes between populations, reduces the probability of hybridization and may further enhance such isolation (Paterson, 1978, 1985; Templeton, 1981, 1989; Coyne and Orr, 1989; Endler, 1989; Coyne, 1992).

Divergence may occur in allopatry resulting in the evolution of efficient mate recognition systems that prevent or reduce interbreeding when the populations come into secondary contact (Mayr, 1963; Templeton, 1981). Alternatively, isolating characters may particularly evolve in areas of secondary contact and, provided hybridization results in less viable or fertile offspring, selection will act against such mating (Fisher, 1930; Dobzhansky, 1940). This process may result in reinforcement of pre-mating isolation that eventually may develop further into reproductive character displacement (Dobzhansky, 1940; Brown and Wilson, 1956). Eventually, populations may become fully reproductively isolated and speciation has occurred. This relationship between sexual selection and speciation may be further enhanced by particularly large variability in the capacity for production and detection of signals used in a mating context.

Although long-standing observations indicate that species have diverged much more in secondary sexual characters than in other phenotypic traits (e.g., Darwin, 1871), this hypothesis has never been tested empirically. Darwin's observation could be addressed in two different ways. First, secondary sexual characters could be more variable among species than ordinary morphological traits. Second, morphological characters could be more variable among species if secondary sexual characters than if non-sexual characters. This second point to some extent also includes the first. The main aim of this paper was to test the first of these points, that is, whether secondary sexual characters vary more among species than other phenotypic traits. Knowledge of this subject may advance our current understanding of the processes of speciation. 


\section{Materials and methods}

Phylogenetic information and definition of secondary sexual feather characters

We have identified all independent evolutionary events of secondary sexual feather characters in birds based on available phylogenetic information (see also Møller and Cuervo, 1998; Cuervo and Møller, 1999). By a secondary sexual feather character we mean a character that is completely restricted to one sex, or that is considerably larger in one sex than the other. Specific criteria are given below. We excluded cases of extravagant feather characters in both sexes when there was no sexual size dimorphism, although mutual sexual selection may account for such exaggerated monomorphism (Jones and Hunter, 1993). We admit that more studies have to be performed before we can dismiss mutual sexual selection as an important factor in the evolution of exaggerated sexual size monomorphism. For the time being we assume that extravagant sexually size dimorphic traits are associated with sexual selection, as demonstrated by numerous observational and experimental studies (see Andersson, 1994). Sexual size monomorphism was not the subject of the present study. Furthermore, we have not considered feather color or naked skin patches in the present study. Sexually size dimorphic traits were considered to qualify as a secondary sexual character if there was a sex difference in their size of at least $5 \%$ because previous studies have considered this cut-off point for dimorphism (Höglund, 1989; Oakes, 1992; Höglund and Sillén-Tullberg, 1994). If we suspected that a species might be sexually size dimorphic, we investigated this by measuring ten males and ten females of the species in question. A total of 82 such cases resulted in 12 being considered sexually size monomorphic and the remaining 70 being size dimorphic. A few species could not be included in our data set due to a shortage of specimens in the museum collections visited. Species with a feather character only being expressed in males were all included in the study. In three species (Pteridophora alberti, Pavo cristatus, and Pipra cornuta), only males were available. We could not measure secondary sexual characters in female Rollulus rouloul because female specimens had these feathers in a poor state.

We used the phylogeny of Sibley and Ahlquist (1990), based on DNA-DNA hybridization, to identify different evolutionary events of extravagant secondary sexual feather characters. For the family Hirundinidae, we used the phylogeny of Sheldon and Winkler (1993). Secondary sexual feather characters have evolved a large number of times. If no other information was available, we assumed that there was only a single evolutionary event in each family. If secondary sexual feather characters appeared in subfamilies or tribes that were phylogenetically separated, these were considered to be different evolutionary 
events. However, if for example a secondary sexual tail had evolved in one species and a secondary sexual head plume had evolved in another species of the same family, we assumed that they represented two different evolutionary events, since these traits were obviously developmentally and morphologically independent. If more than a single species with secondary sexual feather characters occurred within a taxon, we exclusively used abundance as the criterion for choice of a species due to more museum specimens being available for abundant species. The phylogenetic relationships among the 70 species included in our study are shown in Figure 1.

\section{Data collection and calculations}

For each species we measured ten adults of each sex in major museum collections (see Acknowledgments), although it was impossible to obtain this number of specimens in some cases. The mean number of specimens per species and sex was $9.9 \pm 0.4 \mathrm{SD}$, with a minimum value of 7 . Specimens were chosen in the order in which they appeared in the collections, which prevents any involuntary bias in sampling. We have previously shown that estimates of phenotypic variation of secondary sexual feather characters obtained from museum samples are very similar to estimates obtained from the field (Cuervo and Møller, 1999). We only included adult specimens in breeding plumage and good feather condition. Individuals with broken or worn feathers were excluded. We were especially careful to exclude specimens in molt by checking for the presence of feather quills. All specimens of each species belonged to the same subspecies and, when possible, to the same population. In Hydrophasianus chirurgus females had secondary sexual feather characters, apparently due to the polyandrous mating system.

We chose a number of standard morphological characters for measurements. These included the secondary sexual feather character, two feather characters that represented ordinary morphological feather characters (wing length and tail length) and a skeletal character (tarsus length) that is a standard measure of skeletal body size in studies of birds. We measured the length of the left and the right secondary sexual feather characters (with a ruler to the nearest $\mathrm{mm}$; usually elongated tail feathers or crests, but sometimes elongated feathers in wings and other feather tracts), flattened wing (with a ruler to the nearest $\mathrm{mm}$ ), tail (with a ruler to the nearest $\mathrm{mm}$ ), and tarsus (with a digital caliper to the nearest $0.1 \mathrm{~mm}$ ) according to Svensson (1984). Tail length was only used as a character in species where tail feathers were not the secondary sexual feather characters. The size of characters was defined as the mean of the left and the right character. A complete list of species and mean (SE) size for the different characters is provided in Table 1. 


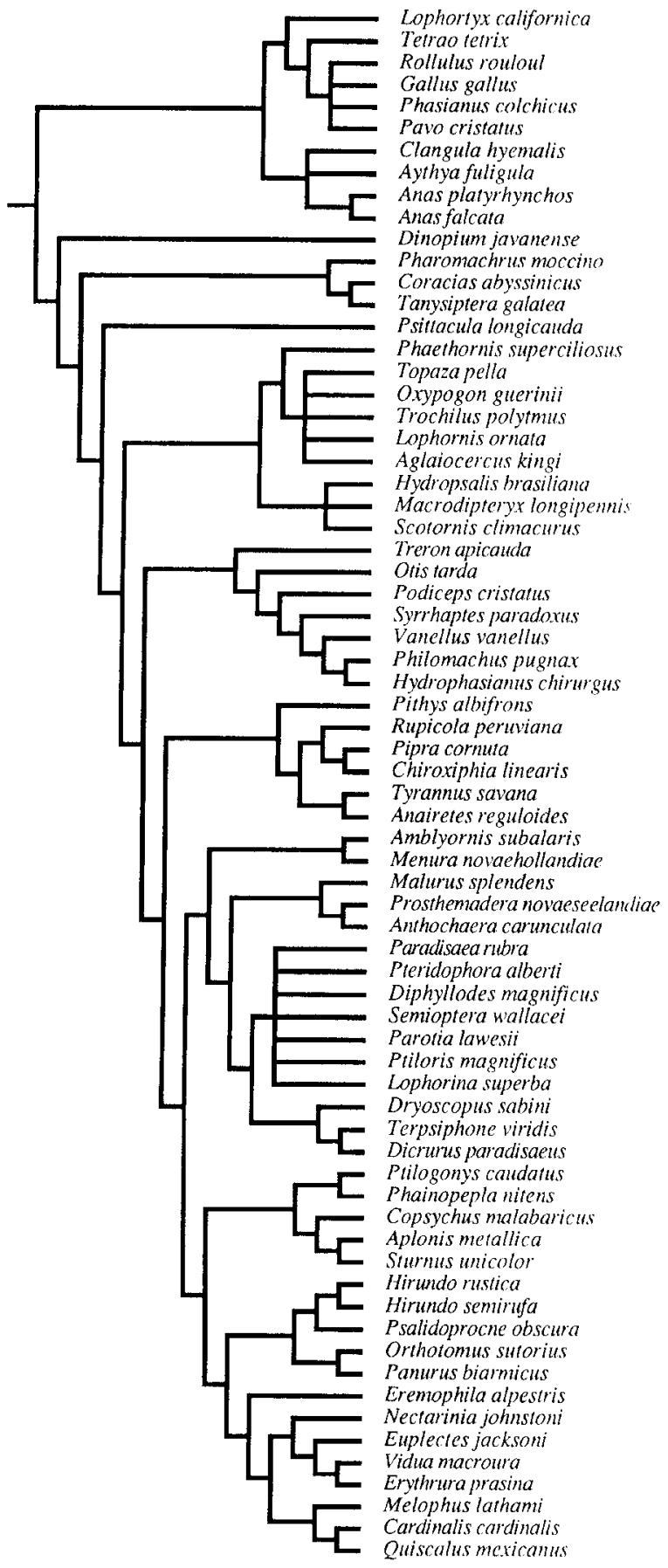

Figure 1. Phylogenetic relationships based on Sibley and Ahlquist (1990) and Sheldon and Winkler (1993) among the 70 bird species with secondary sexual feather characters included in this study. 
Table 1. Mean (SE) size (mm) of morphological characters in bird species with secondary sexual characters

\begin{tabular}{|c|c|c|c|c|c|c|}
\hline Species & ${ }^{\mathrm{a}} \mathrm{Sex}$ & $N$ & Wing & Tail & Tarsus & Ornament \\
\hline Aglaiocercus kingi & $\mathrm{m}$ & 10 & $70.25(0.44)$ & - & $6.18(0.04)$ & $127.95(3.64)$ \\
\hline Outer tail feathers & f & 10 & $58.00(0.59)$ & - & $6.31(0.08)$ & $41.25(1.07)$ \\
\hline Amblyornis subalaris & $\mathrm{m}$ & 10 & $122.25(0.74)$ & $90.70(0.80)$ & $34.40(0.43)$ & $37.50(0.82)$ \\
\hline Crown feathers & $f$ & 10 & $122.75(1.19)$ & $88.85(0.84)$ & $34.98(0.40)$ & - \\
\hline Anairetes reguloides & $\mathrm{m}$ & 8 & $52.06(0.63)$ & $50.63(2.29)$ & $20.09(0.24)$ & $17.88(0.85)$ \\
\hline Crown feathers & f & 7 & $49.93(0.56)$ & $47.79(0.53)$ & $19.61(0.47)$ & $15.86(0.81)$ \\
\hline Anas falcata & $\mathrm{m}$ & 10 & $250.20(1.63)$ & $65.55(1.68)$ & $37.75(0.46)$ & $182.45(3.28)$ \\
\hline Wing feathers & $\mathrm{f}$ & 10 & $231.05(1.23)$ & $68.60(1.11)$ & $36.43(0.37)$ & $100.70(3.50)$ \\
\hline Anas platyrhynchos & $\mathrm{m}$ & 10 & $269.00(4.19)$ & $82.50(1.01)$ & $43.90(0.53)$ & $64.20(2.38)$ \\
\hline Central tail feathers & $\mathrm{f}$ & 10 & $249.50(2.84)$ & $79.40(1.10)$ & $41.65(0.61)$ & - \\
\hline Anthochaera carunculata & $\mathrm{m}$ & 10 & $154.95(1.92)$ & - & $34.48(0.28)$ & $159.95(3.85)$ \\
\hline Central tail feathers & $\mathrm{f}$ & 10 & $144.95(2.84)$ & - & $33.37(0.35)$ & $147.00(2.27)$ \\
\hline Aplonis metallica & $\mathrm{m}$ & 10 & $110.60(0.41)$ & - & $22.39(0.21)$ & $99.00(1.54)$ \\
\hline Central tail feathers & $\mathrm{f}$ & 10 & $106.15(1.06)$ & - & $22.44(0.25)$ & $94.05(1.81)$ \\
\hline Aythya fuligula & $\mathrm{m}$ & 10 & $203.25(1.55)$ & $53.25(0.83)$ & $33.86(0.27)$ & $62.30(2.83)$ \\
\hline Crown feathers & $\mathrm{f}$ & 10 & $194.50(1.34)$ & $49.80(0.57)$ & $33.49(0.16)$ & $24.10(2.76)$ \\
\hline Cardinalis cardinalis & $\mathrm{m}$ & 10 & $95.48(1.00)$ & $102.08(1.73)$ & $24.56(0.25)$ & $30.30(0.67)$ \\
\hline Crown feathers & $\mathrm{f}$ & 10 & $91.65(0.76)$ & $96.25(1.09)$ & $24.50(0.21)$ & $28.80(0.60)$ \\
\hline Chiroxiphia linearis & $\mathrm{m}$ & 10 & $71.15(0.41)$ & - & $18.39(0.38)$ & $141.75(4.06)$ \\
\hline Central tail feathers & $\mathrm{f}$ & 10 & $70.15(0.60)$ & $34.30(0.53)$ & $18.23(0.18)$ & $54.30(1.93)$ \\
\hline Clangula hyemalis & $\mathrm{m}$ & 10 & $227.75(2.39)$ & - & $34.42(0.41)$ & $201.45(7.99)$ \\
\hline Central tail feathers & $\mathrm{f}$ & 10 & $209.10(2.37)$ & $66.45(2.05)$ & $33.06(0.31)$ & - \\
\hline Copsychus malabaricus & $\mathrm{m}$ & 10 & $96.50(0.85)$ & - & $25.68(0.22)$ & $171.60(6.23)$ \\
\hline Central tail feathers & $\mathrm{f}$ & 10 & $92.00(1.38)$ & - & $25.19(0.28)$ & $134.00(2.99)$ \\
\hline Coracias abyssinicus & $\mathrm{m}$ & 10 & $161.90(0.88)$ & $123.80(1.24)$ & $22.55(0.32)$ & $238.75(5.73)$ \\
\hline Outer tail feathers & $\mathrm{f}$ & 10 & $159.60(1.80)$ & $124.95(1.91)$ & $22.27(0.39)$ & $226.85(5.02)$ \\
\hline Dicrurus paradisaeus & $\mathrm{m}$ & 10 & $161.80(2.06)$ & - & $26.70(0.37)$ & $356.25(15.82)$ \\
\hline Outer tail feathers & $\mathrm{f}$ & 10 & $156.05(1.86)$ & - & $25.94(0.47)$ & $322.50(9.08)$ \\
\hline Dinopium javanense & $\mathrm{m}$ & 10 & $133.15(2.10)$ & $95.95(1.85)$ & $23.45(0.25)$ & $23.80(0.42)$ \\
\hline Crown feathers & $\mathrm{f}$ & 10 & $129.65(1.45)$ & $95.60(1.40)$ & $22.20(0.30)$ & $21.60(0.95)$ \\
\hline Diphyllodes magnificus & $\mathrm{m}$ & 10 & $113.75(0.85)$ & $43.50(0.68)$ & $32.15(0.14)$ & $41.00(1.00)$ \\
\hline Neck tuft & $\mathrm{f}$ & 10 & $107.70(0.54)$ & $62.80(1.28)$ & $30.15(0.23)$ & - \\
\hline Dryoscopus sabini & $\mathrm{m}$ & 10 & $84.40(0.98)$ & $69.70(0.66)$ & $24.78(0.40)$ & $34.20(0.49)$ \\
\hline Upper tail coverts & $\mathrm{f}$ & 10 & $80.60(0.73)$ & $69.05(1.05)$ & $24.05(0.14)$ & $32.00(0.70)$ \\
\hline Eremophila alpestris & $\mathrm{m}$ & 10 & $109.40(0.73)$ & $70.70(1.10)$ & $22.24(0.28)$ & $9.53(0.20)$ \\
\hline Crown feathers & $\mathrm{f}$ & 10 & $102.45(1.14)$ & $61.55(0.94)$ & $21.42(0.33)$ & $7.69(0.25)$ \\
\hline Erythrura prasina & $\mathrm{m}$ & 10 & $58.73(0.22)$ & - & $14.56(0.08)$ & $59.63(1.38)$ \\
\hline Central tail feathers & $\mathrm{f}$ & 10 & $59.53(0.31)$ & - & $14.67(0.11)$ & $41.38(1.14)$ \\
\hline Euplectes jacksoni & $\mathrm{m}$ & 10 & $92.10(0.76)$ & - & $28.27(0.22)$ & $208.40(2.11)$ \\
\hline Central tail feathers & $\mathrm{f}$ & 10 & $84.10(0.69)$ & $50.00(0.99)$ & $28.85(0.19)$ & - \\
\hline Gallus gallus & $\mathrm{m}$ & 10 & $232.30(3.24)$ & - & $69.23(1.03)$ & $105.30(3.66)$ \\
\hline Neck feathers & $\mathrm{f}$ & 10 & $198.50(1.84)$ & $149.45(2.01)$ & $59.42(0.64)$ & $54.35(1.41)$ \\
\hline Hirundo rustica & $\mathrm{m}$ & 10 & $127.50(1.29)$ & - & $11.56(0.11)$ & $111.85(2.27)$ \\
\hline Outer tail feathers & $\mathrm{f}$ & 10 & $125.90(0.89)$ & - & $11.35(0.14)$ & $91.55(2.26)$ \\
\hline Hirundo semirufa & $\mathrm{m}$ & 10 & $118.25(1.21)$ & - & $14.20(0.17)$ & $114.50(4.24)$ \\
\hline Outer tail feathers & f & 10 & $117.15(1.11)$ & - & $14.19(0.19)$ & $102.15(2.93)$ \\
\hline Hydrophasianus chirurgus & $\mathrm{m}$ & 10 & $197.35(4.61)$ & - & $51.58(1.32)$ & $240.30(13.31)$ \\
\hline Central tail feathers & f & 10 & $221.55(4.50)$ & - & $55.90(0.98)$ & $287.65(13.25)$ \\
\hline
\end{tabular}


Table 1. (Continued)

\begin{tabular}{|c|c|c|c|c|c|c|}
\hline Species & ${ }^{a} \operatorname{Sex}$ & $N$ & Wing & Tail & Tarsus & Ornament \\
\hline Hydropsalis brasiliana & $\mathrm{m}$ & 10 & $176.45(3.26)$ & - & $18.52(0.29)$ & $285.55(15.71)$ \\
\hline Outer tail feathers & $\mathrm{f}$ & 10 & $171.30(1.93)$ & - & $18.86(0.31)$ & $148.55(4.57)$ \\
\hline Lophorina superba & $\mathrm{m}$ & 10 & $130.60(0.80)$ & $90.30(0.53)$ & $32.67(0.27)$ & $122.60(1.90)$ \\
\hline Cape & $\mathrm{f}$ & 10 & $115.80(1.03)$ & $82.30(1.05)$ & $29.87(0.32)$ & - \\
\hline Lophornis ornata & $\mathrm{m}$ & 10 & $39.90(0.32)$ & $24.95(0.40)$ & - & $20.93(0.64)$ \\
\hline Throat plumes & $\mathrm{f}$ & 10 & $37.80(0.29)$ & $21.40(0.22)$ & - & - \\
\hline Lophortyx californica & $\mathrm{m}$ & 10 & $113.78(0.89)$ & $83.90(0.88)$ & $29.96(0.38)$ & $32.70(0.72)$ \\
\hline Crown feathers & $\mathrm{f}$ & 10 & $111.23(0.78)$ & $80.80(1.66)$ & $28.56(0.20)$ & $19.90(0.80)$ \\
\hline Macrodipteryx longipennis & $\mathrm{m}$ & 10 & $179.45(1.28)$ & - & $19.64(0.18)$ & $450.30(12.17)$ \\
\hline Wing feathers & $\mathrm{f}$ & 10 & $168.55(0.97)$ & $97.80(1.23)$ & $19.42(0.21)$ & - \\
\hline Malurus splendens & $\mathrm{m}$ & 10 & $51.40(0.26)$ & $60.25(0.55)$ & $22.06(0.17)$ & $8.45(0.16)$ \\
\hline Moustache & $\mathrm{f}$ & 10 & $50.20(0.62)$ & $58.17(0.76)$ & $21.73(0.26)$ & - \\
\hline Melophus lathami & $\mathrm{m}$ & 10 & $84.70(0.51)$ & $70.88(1.19)$ & $20.64(0.20)$ & $24.50(0.48)$ \\
\hline Crown feathers & $\mathrm{f}$ & 10 & $77.93(0.68)$ & $66.75(1.01)$ & $20.35(0.18)$ & $16.00(0.40)$ \\
\hline Menura novaehollandiae & $\mathrm{m}$ & 10 & $293.35(2.46)$ & - & $110.85(1.21)$ & $612.45(23.56)$ \\
\hline Central tail feathers & $\mathrm{f}$ & 8 & $272.19(6.38)$ & - & $104.87(2.47)$ & $482.81(9.86)$ \\
\hline Nectarinia johnstoni & $\mathrm{m}$ & 10 & $79.45(1.13)$ & - & $16.74(0.19)$ & $155.70(6.80)$ \\
\hline Central tail feathers & $\mathrm{f}$ & 10 & $71.55(1.20)$ & $50.80(1.18)$ & $17.80(0.52)$ & - \\
\hline Orthotomus sutorius & $\mathrm{m}$ & 10 & $50.03(0.57)$ & - & $19.10(0.06)$ & $78.05(4.55)$ \\
\hline Central tail feathers & $\mathrm{f}$ & 10 & $46.68(0.49)$ & - & $19.65(0.13)$ & $38.30(1.00)$ \\
\hline Otis tarda & $\mathrm{m}$ & 10 & $603.50(7.66)$ & $242.65(3.43)$ & $156.18(3.59)$ & $128.90(6.31)$ \\
\hline Moustache & $\mathrm{f}$ & 10 & $470.30(4.62)$ & $210.65(2.38)$ & $116.98(1.69)$ & $23.40(2.27)$ \\
\hline Oxypogon guerinii & $\mathrm{m}$ & 10 & $73.35(0.47)$ & $54.85(0.57)$ & $7.25(0.07)$ & $19.35(0.61)$ \\
\hline Crown feathers & $\mathrm{f}$ & 10 & $66.15(0.48)$ & $45.89(0.96)$ & $7.26(0.17)$ & - \\
\hline Panurus biarmicus & $\mathrm{m}$ & 10 & $60.00(0.48)$ & $83.50(1.42)$ & $20.42(0.21)$ & $12.05(0.25)$ \\
\hline Moustache & $\mathrm{f}$ & 10 & $58.15(0.26)$ & $77.25(0.88)$ & $20.15(0.17)$ & $9.40(0.19)$ \\
\hline Paradisaea rubra & $\mathrm{m}$ & 10 & $168.80(1.00)$ & - & $43.44(0.37)$ & $517.00(4.84)$ \\
\hline Central tail feathers & f & 10 & $152.60(1.55)$ & $119.00(1.00)$ & $40.95(0.80)$ & - \\
\hline Parotia lawesii & $\mathrm{m}$ & 10 & $156.85(1.95)$ & - & $47.76(0.85)$ & $24.00(0.47)$ \\
\hline Breast shield & $\mathrm{f}$ & 10 & $148.75(1.77)$ & $99.90(0.92)$ & $49.69(0.76)$ & - \\
\hline Pavo cristatus & $\mathrm{m}$ & 10 & $456.75(3.42)$ & $509.33(12.30)$ & $135.16(2.83)$ & $1529.45(46.68)$ \\
\hline Tail coverts & $\mathrm{f}$ & - & - & - & - & - \\
\hline Phaethornis superciliosus & $\mathrm{m}$ & 10 & $59.55(0.41)$ & - & - & $72.10(0.74)$ \\
\hline Central tail feathers & $\mathrm{f}$ & 10 & $60.20(1.02)$ & - & - & $68.65(1.01)$ \\
\hline Phainopepla nitens & $\mathrm{m}$ & 10 & $93.75(0.80)$ & $96.85(0.96)$ & $18.06(0.23)$ & $25.50(0.37)$ \\
\hline Crown feathers & $\mathrm{f}$ & 10 & $91.85(1.36)$ & $91.70(1.69)$ & $18.32(0.27)$ & $20.80(0.49)$ \\
\hline Pharomachrus mocinno & $\mathrm{m}$ & 10 & $210.30(1.73)$ & - & $21.17(0.55)$ & $752.45(29.94)$ \\
\hline Tail coverts & $\mathrm{f}$ & 10 & $218.20(2.24)$ & - & $20.81(0.14)$ & $177.80(4.42)$ \\
\hline Phasianus colchicus & $\mathrm{m}$ & 10 & $245.60(2.64)$ & - & $70.39(1.40)$ & $458.90(13.82)$ \\
\hline Central tail feathers & $\mathrm{f}$ & 10 & $220.65(1.95)$ & - & $61.70(0.62)$ & $277.65(8.31)$ \\
\hline Philomachus pugnax & $\mathrm{m}$ & 10 & $186.10(1.33)$ & $69.70(0.82)$ & $51.33(0.36)$ & $39.45(1.34)$ \\
\hline Neck tuft & $\mathrm{f}$ & 10 & $153.10(1.03)$ & $58.10(1.22)$ & $41.60(0.42)$ & - \\
\hline Pipra cornuta & $\mathrm{m}$ & 10 & $66.55(0.43)$ & $43.45(0.40)$ & $18.00(0.11)$ & $15.40(0.32)$ \\
\hline Crown feathers & $\mathrm{f}$ & - & - & - & - & - \\
\hline Pithys albifrons & $\mathrm{m}$ & 10 & $72.55(0.57)$ & $39.00(1.00)$ & $22.14(0.30)$ & $20.80(1.05)$ \\
\hline Crown feathers & $\mathrm{f}$ & 10 & $70.15(0.65)$ & $37.25(0.69)$ & $22.04(0.18)$ & $17.45(0.68)$ \\
\hline Podiceps cristatus & $\mathrm{m}$ & 10 & $188.50(1.44)$ & - & $63.84(0.87)$ & $39.95(1.27)$ \\
\hline Ear tuft & $\mathrm{f}$ & 10 & $183.85(1.73)$ & - & $62.34(0.86)$ & $36.30(1.32)$ \\
\hline $\begin{array}{l}\text { Prosthemadera } \\
\text { novaeseelandiae }\end{array}$ & $\mathrm{m}$ & 10 & $151.95(2.05)$ & $121.35(2.02)$ & $38.61(0.34)$ & $33.45(0.93))$ \\
\hline
\end{tabular}


Table 1. (Continued)

\begin{tabular}{|c|c|c|c|c|c|c|}
\hline Species & ${ }^{\mathrm{a}} \mathrm{Sex}$ & $N$ & Wing & Tail & Tarsus & Ornament \\
\hline Neck feathers & $\mathrm{f}$ & 10 & $140.85(2.26)$ & $115.65(1.98)$ & $36.22(0.81)$ & $30.65(1.05)$ \\
\hline Psalidoprocne obscura & $\mathrm{m}$ & 10 & $97.35(0.76)$ & - & $9.41(0.18)$ & $97.85(3.51)$ \\
\hline Outer tail feathers & $\mathrm{f}$ & 9 & $88.28(0.83)$ & - & $9.25(0.25)$ & $68.67(2.96)$ \\
\hline Psittacula longicauda & $\mathrm{m}$ & 10 & $178.68(0.90)$ & - & $17.48(0.11)$ & $242.88(3.30)$ \\
\hline Central tail feathers & $\mathrm{f}$ & 10 & $169.25(1.62)$ & - & $17.75(0.17)$ & $180.40(7.65)$ \\
\hline Pteridophora alberti & $\mathrm{m}$ & 9 & $123.89(1.29)$ & $87.56(1.06)$ & $31.85(0.27)$ & $435.11(15.26)$ \\
\hline Crown feathers & $\mathrm{f}$ & - & - & - & - & - \\
\hline Ptilogonys caudatus & $\mathrm{m}$ & 10 & $97.10(0.61)$ & - & $18.67(0.19)$ & $133.10(2.77)$ \\
\hline Central tail feathers & $\mathrm{f}$ & 7 & $94.71(0.71)$ & - & $18.64(0.32)$ & $116.07(2.11)$ \\
\hline Ptiloris magnificus & $\mathrm{m}$ & 10 & $186.45(0.96)$ & $106.05(1.03)$ & $41.48(0.37)$ & $179.30(4.42)$ \\
\hline Flank plumes & $\mathrm{f}$ & 10 & $156.30(1.86)$ & $102.35(1.15)$ & $37.26(0.58)$ & $72.90(2.13)$ \\
\hline Quiscalus mexicanus & $\mathrm{m}$ & 10 & $199.45(2.67)$ & - & $51.22(0.65)$ & $199.60(6.48)$ \\
\hline Central tail feathers & $\mathrm{f}$ & 10 & $160.40(2.07)$ & - & $41.94(0.59)$ & $149.95(4.62)$ \\
\hline Rollulus rouloul & $\mathrm{m}$ & 10 & $140.30(1.53)$ & $62.70(1.63)$ & $43.41(0.25)$ & $37.50(1.72)$ \\
\hline Crown feathers & $\mathrm{f}$ & 10 & $139.95(0.92)$ & $63.00(1.43)$ & $43.09(0.39)$ & - \\
\hline Rupicola peruviana & $\mathrm{m}$ & 10 & $191.25(1.13)$ & $125.55(1.05)$ & $39.07(0.54)$ & $30.45(0.67)$ \\
\hline Crown feathers & $\mathrm{f}$ & 10 & $181.40(1.79)$ & $121.22(0.74)$ & $36.99(0.67)$ & $20.05(0.81)$ \\
\hline Scotornis climacurus & $\mathrm{m}$ & 10 & $142.30(1.21)$ & - & $16.87(0.17)$ & $218.45(7.58)$ \\
\hline Central tail feathers & $\mathrm{f}$ & 10 & $143.45(1.42)$ & - & $16.74(0.19)$ & $172.35(5.10)$ \\
\hline Semioptera wallacei & $\mathrm{m}$ & 10 & $153.65(0.79)$ & $87.55(1.46)$ & $42.38(0.30)$ & $158.90(2.46)$ \\
\hline Wing feathers & $\mathrm{f}$ & 10 & $143.45(1.96)$ & $88.25(1.18)$ & $40.69(0.33)$ & - \\
\hline Sturnus unicolor & $\mathrm{m}$ & 10 & $130.90(0.45)$ & $65.20(0.81)$ & $29.79(0.22)$ & $32.60(1.22)$ \\
\hline Throat feathers & $\mathrm{f}$ & 10 & $127.20(0.79)$ & $61.75(0.75)$ & $29.42(0.31)$ & $22.70(0.94)$ \\
\hline Syrrhaptes paradoxus & $\mathrm{m}$ & 10 & $237.65(6.29)$ & - & - & $167.90(6.87)$ \\
\hline Central tail feathers & $\mathrm{f}$ & 10 & $225.70(2.28)$ & - & - & $126.55(3.30)$ \\
\hline Tanysiptera galatea & $\mathrm{m}$ & 10 & $108.60(0.83)$ & - & $18.00(0.08)$ & $242.55(4.70)$ \\
\hline Central tail feathers & $\mathrm{f}$ & 10 & $107.95(1.53)$ & - & $17.84(0.09)$ & $204.00(10.20)$ \\
\hline Terpsiphone viridis & $\mathrm{m}$ & 10 & $84.65(1.13)$ & - & $16.91(0.29)$ & $272.55(13.20)$ \\
\hline Central tail feathers & $\mathrm{f}$ & 10 & $77.30(0.72)$ & - & $16.06(0.21)$ & $85.95(3.08)$ \\
\hline Tetrao tetrix & $\mathrm{m}$ & 10 & $254.85(1.55)$ & - & $47.86(0.59)$ & $173.50(3.87)$ \\
\hline Outer tail feathers & $\mathrm{f}$ & 10 & $223.70(2.79)$ & - & $44.22(0.51)$ & $105.20(2.51)$ \\
\hline Topaza pella & $\mathrm{m}$ & 10 & $85.00(0.66)$ & - & $10.11(0.05)$ & $21.91(0.43)$ \\
\hline Breast feathers & $\mathrm{f}$ & 10 & $75.75(0.49)$ & $45.10(0.36)$ & $6.89(0.11)$ & - \\
\hline Treron apicauda & $\mathrm{m}$ & 10 & $172.05(1.68)$ & - & $25.70(0.33)$ & $181.50(2.39)$ \\
\hline Central tail feathers & $\mathrm{f}$ & 10 & $167.90(1.31)$ & - & $24.55(0.31)$ & $150.55(4.08)$ \\
\hline Trochilus polytmus & $\mathrm{m}$ & 10 & $66.60(0.60)$ & - & $6.09(0.08)$ & $169.50(3.85)$ \\
\hline 2nd outer tail feathers & $\mathrm{f}$ & 10 & $57.44(0.56)$ & - & $5.66(0.08)$ & $39.75(1.30)$ \\
\hline Tyrannus savana & $\mathrm{m}$ & 10 & $111.35(1.39)$ & - & $17.80(0.19)$ & $239.25(10.46)$ \\
\hline Outer tail feathers & $\mathrm{f}$ & 10 & $105.40(0.92)$ & - & $17.51(0.16)$ & $178.00(7.33)$ \\
\hline Vanellus vanellus & $\mathrm{m}$ & 10 & $224.60(1.56)$ & $98.45(1.56)$ & $50.73(0.39)$ & $78.45(2.67)$ \\
\hline Crown feathers & $\mathrm{f}$ & 10 & $222.10(2.14)$ & $97.90(1.21)$ & $49.89(0.45)$ & $52.60(3.79)$ \\
\hline Vidua macroura & $\mathrm{m}$ & 10 & $73.40(0.77)$ & - & $16.65(0.20)$ & $215.45(5.03)$ \\
\hline Central tail feathers & $\mathrm{f}$ & 10 & $69.68(1.05)$ & $53.60(0.73)$ & $16.31(0.16)$ & - \\
\hline
\end{tabular}

${ }^{\mathrm{a}}$ Type of secondary sexual feather character is indicated. $\mathrm{m}=$ male, $\mathrm{f}=$ female.

We assessed the repeatabilities of our measurements in four species with different kinds of secondary sexual feather characters and different body sizes (Anas platyrhynchos, Hirundo rustica, Sturnus unicolor, and Vanellus vanellus) by measuring the same individuals on two different days without knowledge of 
the results obtained on the first day. Repeatabilities (Becker, 1984) were large (between 0.985 and 0.999 ), suggesting that our measurements were sufficiently precise to allow quantitative analyses, without any indication that small species had larger measurement errors than large species (in all 28 analyses $31,32 \geq d f \geq 27,28, F \geq 131.3, p<0.0001)$.

Secondary sexual feather characters included in this study could in most cases be classified into two categories: tail feathers and head feathers. Secondary sexual tail feathers differ from secondary sexual head feathers, since tail feathers are aerodynamically much more important, and they are also much longer, relative to body size, than head feathers. Moreover, when comparing secondary sexual feathers with wing feathers, all wing feathers belong to the same feather tract, while secondary sexual feathers belong to many different tracts (e.g., head, wing, rectrices). The heterogeneity of secondary sexual characters could inflate the divergence for that kind of trait when comparing with more homogeneous wing or tail feathers. Therefore, a separate analysis of species with similar secondary sexual feather characters is required. This was done for species with secondary sexual rectrices (hereafter secondary sexual tail feathers) and species with secondary sexual head feather: crests, mustaches, head plumes, neck and throat feathers (hereafter secondary sexual head feathers) (see Table 1). Furthermore, since the previous categories of secondary sexual feathers are also partly heterogeneous, we also made separate analyses for species with exactly the same secondary sexual character: species with secondary sexual central tail feathers and species with secondary sexual crown feathers (see Table 1). We have not analyzed separately species with secondary sexual outer tail feathers because sample size (number of standardized linear contrasts) was smaller than 10 .

We analyzed separately $\log _{10}$-transformed mean trait length values for each sex and trait using the Crunch algorithm of CAIC (Comparative Analyses by Independent Contrasts; Purvis and Rambaut, 1995), assessing independent standardized linear contrasts. This method is based on theoretical developments by Felsenstein $(1985,1988)$. The standardized contrasts are in fact estimates of the rate of evolutionary change, so it is possible to determine whether different characters have evolved at different rates, or whether a character has been evolving more rapidly in some clades than in others (Garland, 1992; Martins, 1994; Purvis and Rambaut, 1995). Some authors have presented other methods to estimate rates of evolutionary change in continuous characters using comparative data (Gingerich, 1993; Martins, 1994; Gittleman et al., 1996). While some methods might bias the estimates of rates of evolution due to statistical non-independence in the data and lack of an explicit null model of phenotypic evolution (Gittleman et al., 1996), other methods (Martins, 1994) accounts for sampling error in the means, for heteroscedasticity of variances, for statistical non-independence, and for non-normality of data. However, 
Martins' method needs pairs of closely related species to be applied. Since our data set does not include pairs of species but different species with secondary sexual feathers across all birds, we have chosen the method by Purvis and Rambaut (1995) which can yield rates of evolutionary change, simultaneously controls for statistical non-independence of data and allows tests of all the evolutionary and statistical assumptions on which the method is based (see below for tests of assumptions). There is only one point for which the method of Purvis and Rambaut does not control, and that is measurement error. However, we have already stated above that in our sample repeatabilities (Becker, 1984) were large and measurement errors small. Discussions on the suitability of different comparative methods can be found elsewhere (Martins and Garland, 1991; Garland et al., 1992, 1993; Purvis et al., 1994).

To compare standardized contrasts between traits we used paired $t$-tests (Sokal and Rohlf, 1995). We were unable to obtain sufficient sample sizes for both sexes for all species, and sample sizes therefore differ among comparisons. Secondary sexual characters were not always expressed in both sexes, and the sample size for females for this character was therefore smaller than that for males. Tail length was only used as a character in the species where the tail was not a secondary sexual character. Thus, there was only a small number of observations available for this character. Since data were unavailable for all characters of all species, we made comparisons of standardized contrasts using estimates for the different characters for exactly the same species. For example, information on tail length was only available for males of 32 species, and the comparison of contrasts in tail length and the length of secondary sexual characters was therefore restricted to this sample of 32 species. For each comparison between traits we repeated CAIC and obtained standardized contrasts only for the species included in that particular analysis. We used a model of gradual evolution in the analyses, because a model of punctuated evolution did not fulfill the evolutionary assumptions (see below for testing of assumptions). Since we did not have lengths of the phylogeny branches available, we assigned branch lengths according to an algorithm described by Grafen (1989), assuming that the ages of taxa are in direct proportion to the number of species they contain. In order to fulfill both evolutionary and statistical assumptions we had to transform branch lengths following the formula (branch length $\times 4)^{0.65}$.

The standardized contrast method assumes that the evolution of continuous characters can be modeled as a random walk process (Felsenstein, 1985; Purvis and Rambaut, 1995). This evolutionary assumption can be tested by regressing the contrasts on the estimated nodal values in the phylogeny and checking that slopes are not different from zero (Purvis and Rambaut, 1995). Tests of this assumption for the characters analyzed in this study did not reveal any statistically significant regression after sequential Bonferroni-adjustment 
(Rice, 1989) (when tail and central tail feathers are secondary sexual characters $k=6$, when head and crown feathers are secondary sexual characters $k=8$, in all 28 regressions: $32 \geq d f \geq 9, F \leq 6.26, p \geq 0.020$ ). As concerns the statistical assumptions, CAIC assumes equal rates of evolutionary change per unit branch length in all branches of the phylogeny, i.e. homogeneity of variance. This can be readily tested by correlating the absolute values of the contrasts against the ages of the corresponding nodes and checking that these correlations are not statistically significant (Purvis and Rambaut, 1995). Tests of this assumption for the characters analyzed in this study did not reveal any statistically significant correlation after sequential Bonferroni-adjustment (Rice, 1989) ( $k$ values as above, in all 28 correlations: $33 \geq N \geq 10$, $0.089 \geq r \geq-0.567, p \geq 0.024)$. Another important concern in comparative studies is whether results are consistent at different taxonomic levels. To test if that was the case, we have repeated the analyses comparing standardized contrasts between different morphological characters but only using standardized linear contrasts below the level order, that is, only intra-order contrasts. We have found qualitatively similar results to the ones obtained when including all contrasts, as shown in the Results section. We attempted to repeat the analyses by only including intra-family contrasts, but sample size was too small to allow any statistical comparison.

For multiple statistical testing we used sequential Bonferroni-adjustment (Rice, 1989), with a $10 \%$ level of significance to maintain a reasonable power of the statistical tests (Wright, 1992; Chandler, 1995). All tests were two-tailed.

\section{Results}

Standardized linear contrasts showed significantly higher values for secondary sexual feathers than for ordinary morphological traits in both sexes after sequential Bonferroni-adjustment $(k=6)$, with the exception of secondary sexual feathers in females showing a non-significant tendency for larger contrasts than ordinary tail feathers (paired $t$-test; $d f=19, t=2.20, p=0.041$ ) (Fig. 2A). Standardized contrasts of ordinary morphological traits did not differ significantly from one another (Fig. 2A). Since standardized linear contrasts are estimates of the rate of evolutionary change, according to these results we could say that secondary sexual feather characters showed higher rates of evolution than ordinary morphological traits. That is to say, secondary sexual characters would have diverged more than ordinary traits (with the exception of ordinary tail feathers in females).

We re-calculated standardized linear contrasts to compare rates of evolution between sexes, and after sequential Bonferroni-adjustment $(k=4)$, differences in the rate of evolution were only significant for tarsi, with male tarsi diverging 
$N$

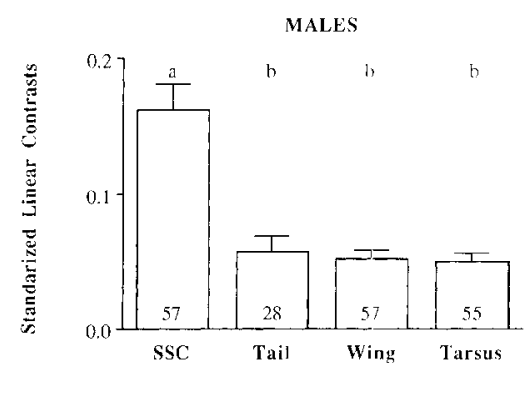

FEMALES

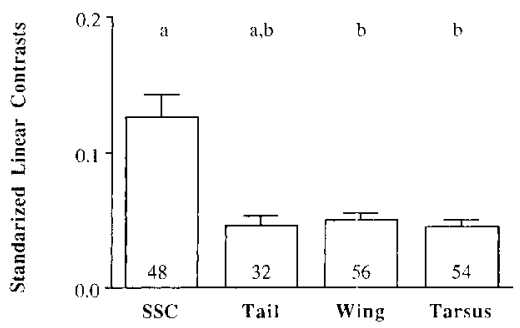

B)

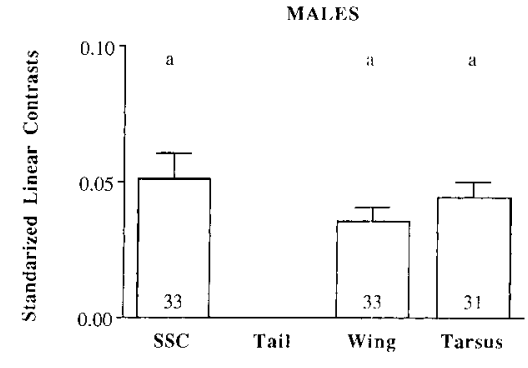

FEMALES

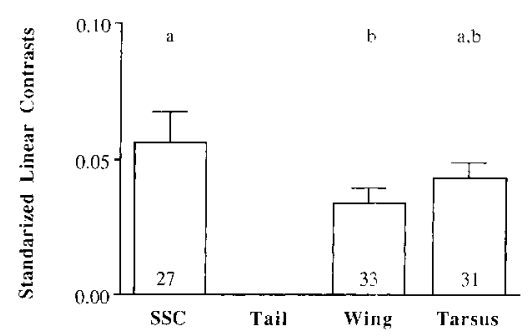

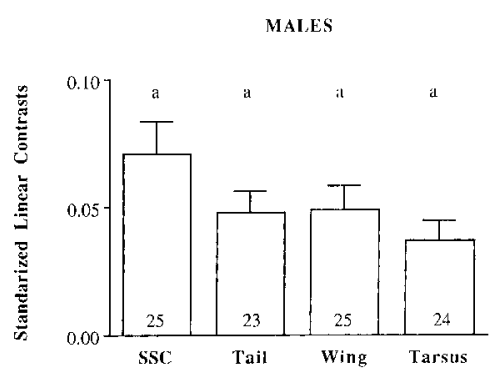

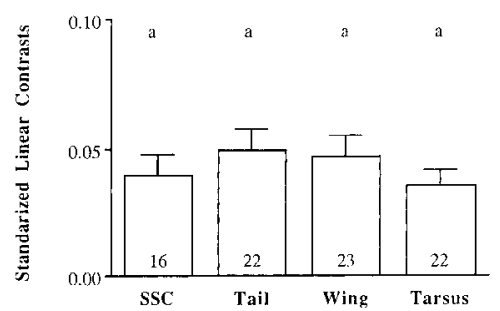

Figure 2. Standardized linear contrasts (mean, SE) for length of four morphological characters in bird species. Sample size (number of contrasts) is indicated. SSC = Secondary sexual character. Different superscripts indicate significant differences in paired $t$-tests at the 0.10 level after sequential Bonferroni-adjustment ( $k=6$ or $k=3$ ). (A) All species. (B) Species with secondary sexual tail feathers. (C) Species with secondary sexual head feathers. 
more than female tarsi (paired $t$-test; secondary sexual feathers: $d f=47$, $t=0.07$, NS; wing feathers: $d f=55, t=1.94$, NS; ordinary tail feathers: $d f=25, t=0.36$, NS; tarsi: $d f=53, t=2.34, p=0.023$ ).

When analyzing separately species with secondary sexual tail feathers and species with secondary sexual head feathers, standardized linear contrasts did not differ significantly among the different types of characters after sequential Bonferroni-adjustment $(k=3$ for species with secondary sexual tail feathers and $k=6$ for species with secondary sexual head feathers) with one exception: in species with secondary sexual tail feathers, female secondary sexual characters diverged more than wing feathers (paired $t$-test, $d f=26, t=2.46$, $p=0.021$ ). In species with secondary sexual head feathers, male secondary sexual characters showed a non-significant tendency to diverge more than tarsi (paired $t$-test, $d f=23, t=2.51, p=0.020$ ) (Figs. 2B and 2C).

We also calculated the statistical power of the paired $t$-tests following Cohen (1988). In general power was moderate $(<50 \%, a=0.05)$ with the exception of the two tests previously mentioned in which secondary sexual characters diverged (or tended to diverge) among species more than ordinary morphological traits (for the comparison secondary sexual tail feathers - wings in females power $=0.68$, for the comparison secondary sexual head feathers tarsi in males power $=0.69$ ). If we assume that the difference in divergence between secondary sexual characters and ordinary morphological characters is of an intermediate magnitude (explaining $5.9 \%$ of the variance, sensu Cohen, 1988) or large (explaining 13.8\% of the variance, sensu Cohen, 1988), we can calculate the sample size needed to achieve a power of $80 \%: 64$ if the difference in divergence is medium and 26 if it is large.

Since secondary sexual tail feathers and secondary sexual head feathers are not completely homogeneous categories of secondary sexual feathers, we made separate analyses for species with exactly the same kind of ornamental feather in the cases where sample size was sufficiently large, i.e. secondary sexual central tail feathers and secondary sexual crown feathers. Results were qualitatively similar to the ones obtained with the broader categories of secondary sexual feathers: standardized linear contrasts did not differ significantly among the different types of characters after sequential Bonferroni-adjustment $(k=3$ for species with secondary sexual central tail feathers and $k=6$ for species with secondary sexual crown feathers) with the exception of secondary sexual central tail feathers diverging more than wing feathers in females (paired $t$-test, $d f=16, t=2.35, p=0.032)$. In the other 17 tests, $22 \geq d f \geq 9$, $1.96 \geq t \geq-2.07, p \geq 0.051$.

To test if the results were consistent at different taxonomic levels we repeated the analyses by only including standardized linear contrasts which had been assessed between taxa or nodes below the level of order (intra-order contrasts). Results were similar to the ones obtained including all nodes, since 
standardized linear contrasts did not differ significantly among the different types of characters after sequential Bonferroni-adjustment $(k=3$ for species with secondary sexual tail feathers and $k=6$ for species with secondary sexual head feathers) except for two cases: in species with secondary sexual tail feathers female secondary sexual characters diverged more than wing feathers (paired $t$-test, $d f=19, t=2.68, p=0.015$ ), and in species with secondary sexual head feathers male secondary sexual characters diverged more than tarsi (paired $t$-test, $d f=17, t=2.82, p=0.012$ ) (notice that this difference did not reach statistical significance when including all contrasts). In the other 16 tests, $24 \geq d f \geq 9,2.31 \geq t \geq-1.23, p \geq 0.034$. Only including species with secondary sexual central tail feathers and intra-order contrasts, rates of evolution did not differ significantly among the different types of characters after sequential Bonferroni-adjustment $(k=3)$ with the exception of female secondary sexual characters diverging more than wing feathers (paired $t$-test, $d f=9, t=3.30, p=0.009)$. In the other 5 tests, $14 \geq d f \geq 8,1.85 \geq t \geq$ $-1.37, p \geq 0.086$. For intra-order contrasts in species with secondary sexual crown feathers, sample size was too small to allow reliable statistical comparisons. We attempted to repeat these analyses by only including intra-family contrasts, i.e. contrasts which had been assessed by comparing nodes or taxa below the family level, but small sample sizes did not allow statistical tests.

\section{Discussion}

Analyses of the evolutionary rate of secondary sexual characters and ordinary morphological characters among bird species with secondary sexual feather characters revealed that secondary sexual characters were more divergent than ordinary morphological traits (Fig. 2A). However, a more appropriate analysis comparing divergence among morphological characters for species with similar kinds of secondary sexual feather characters only revealed significant differences between secondary sexual tail feathers and wing feathers for females (Figs. 2B and 2C). We can conclude that the apparently large divergence of secondary sexual characters when including all species was partly a consequence of heterogeneity of secondary sexual feather characters (tail feathers, crests, wing feathers). We have found that the results were very similar when including all species with secondary sexual tail feathers, or only species with secondary sexual central tail feathers. In the same way, the results were very similar when including all species with secondary sexual head feathers or only species with secondary sexual crown feathers.

Consequently, although secondary sexual tail and head feather characters are not completely homogeneous categories of feather tracts, we can be confident that differences between sub-categories (e.g. outer vs. central tail 
feathers, crown vs. neck feathers) were not sufficiently large to give rise to a noticeable inflated divergence in secondary sexual feather characters.

In species with secondary sexual tail feathers wing length in females diverged significantly less than secondary sexual characters. Moreover, if we only considered intra-order contrasts, we also found that tarsus length diverged significantly less than secondary sexual characters in males of species with secondary sexual head feathers (see Results). At first glance, this result could make us believe that significant differences in the rate of evolution between secondary sexual feathers and other morphological traits are more generalized when only considering apical branches in the phylogeny. However, the results were in fact very similar when including all contrasts or only intra-order contrasts. The difference in the rate of evolution between tarsus length and secondary sexual characters in males of species with secondary sexual head feathers was very close to statistical significance when analyses were based on the entire phylogeny (see Results).

The results are in the predicted direction, with secondary sexual characters diverging more than ordinary morphological traits, partially supporting the general impression, that has persisted since the days of Darwin (1871), that secondary sexual characters are more variable among species than ordinary morphological characters. However, this result is not conclusive because none of the other comparisons between secondary sexual characters and ordinary traits was significant for either sex. We should not forget to take the statistical power of tests into account (Cohen, 1988), and this was generally medium to low (see Results), which indicates that the findings should be interpreted with caution. The two tests previously mentioned in which secondary sexual characters diverged (or tended to diverge) more than ordinary morphological traits have the largest power $(>65 \%)$, and hence are the most reliable. If we assume that the difference in divergence among species between secondary sexual characters and ordinary morphological characters is medium to large (sensu Cohen, 1988), we can calculate the sample size needed to achieve a power of $80 \%$. Such calculations revealed that a sample size of 64 (medium effect size) or 26 (large effect size) was necessary to achieve such a desired power. Given that sample sizes in this study ranged between 25-33 (species with secondary sexual tail feathers) or 15-25 (species with secondary sexual head feathers), we can conclude that at least in species with secondary sexual tail feathers, differences in divergence among characters cannot be large, and that they are medium at most. It is important to emphasize that the most appropriate comparison is that between characters of similar structure, i.e. between feather characters. Possible explanations for the lack of significant differences in divergence between secondary sexual characters and ordinary traits are discussed below.

Sexual selection will obviously affect secondary sexual characters, but ordinary morphological traits might also be affected to some extent, because the 
entire phenotype of species with secondary sexual characters may change to reduce the costs of the secondary sexual characters (Andersson, 1994; Balmford et al., 1994; Møller, 1996). All models of sexual selection assume that secondary sexual characters are costly to produce and maintain, and that individuals with reduced costs of production and maintenance of secondary sexual characters would be at a selective advantage. A number of physiological, morphological and behavioral traits might have evolved as a result of their cost-reducing properties (Møller, 1996). For example, Balmford et al. (1994) found that within long-tailed bird families, variation in the extent of sexual tail dimorphism was associated with covariation in sexual wing dimorphism. Moreover, sexual wing dimorphism was generally greater in bird species with aerodynamically costly graduated tails than in species with cheaper, streamershaped tails. Even if sexual selection plays a role in evolutionary divergence of characters among species, the coevolution of cost-reducing traits may reduce any difference in divergence between secondary sexual characters and ordinary traits.

Evolutionary rates in male characters among bird species were similar to evolutionary rates of homologous characters in females, with the exception of male tarsi diverging more than female tarsi. We have not found significant sexual differences in the rate of evolution for secondary sexual feathers, despite the widely accepted supposition (review in Andersson, 1994) that the intensity of sexual selection is stronger in males as compared to females. This lack of difference in divergence of secondary sexual feathers between sexes could be due to a genetic correlation between the sexes: any selection for increased size of a character among individuals of one sex will result in a correlated response to selection among individuals of the other sex (Falconer, 1989). Consequently, any divergence in male secondary sexual feathers may be associated with divergence in the same female traits. Observational and experimental evidence suggests that feather ornaments of birds play an important role in female choice, but they are of no or little significance in male-male competition (reviews in Andersson, 1994; Møller, 1994). However, the evolutionary forces that are shaping tarsus size are probably very different. Tarsus length is the only skeletal trait included in our analyses, and hence it is the only one we can consider to be a measure of body size. Although body size is mainly considered as an ordinary non-sexual character, sexual selection on males to control access to females favors larger size (McLain, 1993), especially through male-male competition (Clutton-Brock et al., 1977, 1980; Clutton-Brock, 1985). On the other hand, it has been hypothesized that changes of genetic correlations are caused by oppositely directed selection pressures in the two sexes (Lande, 1980; Lande and Arnold, 1985). Therefore, if natural selection pressures against larger body size in females were stronger than natural selection pressures against larger secondary sexual characters in that sex, 
differences in the rate of evolution between sexes would be larger for tarsi as compared to secondary sexual feathers, exactly the result obtained. Obviously, natural selection might also be related to sexual size dimorphism through different roles in parental care (Cuervo and Møller, 2000) or niche partitioning (Selander, 1966) between males and females. Actually, patterns of evolution of sexual dimorphism in birds seem to be far from simple. Burns (1998) showed that in tanagers, female plumage has not evolved as a correlated response to factors affecting male plumage, and Price and Birch (1996) reached similar conclusions studying evolutionary changes between monomorphism and dimorphism in passerine birds. Among blackbirds, Irwin (1994) found that changes in female plumage were due to social selection pressures on females, and that they evolved plumage changes more frequently than males. In other bird families Martin and Badyaev (1996) demonstrated that female plumage changes were related to different degrees of nest predation, while that was not the case for male plumage. In some species males have been shown to prefer females with secondary sexual characters (Johnson, 1988; Hill, 1993; Jones and Hunter, 1993), sexual selection thereby clearly affecting females directly. Therefore, many other factors apart from sexual selection on males and genetic correlations between the sexes might affect the evolution of female characters. However, none of these factors gave rise to differences in divergence between male and female secondary sexual feathers. Although many different natural selection forces (e.g. parental roles) may influence the evolution of sexual tarsus size dimorphism, the effect of sexual selection on males favoring larger tarsi and the detrimental effect of natural selection on females against larger tarsi might explain, at least partially, the sexual difference in divergence in tarsus length.

A consequence of the similarity in divergence of secondary sexual characters in males and homologous characters in females is that male traits that are costly to develop and maintain should be particularly costly for females because of greater female costs of reproduction. Although females, as we have seen, may benefit directly from sexual selection, the intensity of this selection is supposedly stronger in males (review in Andersson, 1994). There is considerable evidence for secondary sexual characters being costly to develop and maintain for males (review in Andersson, 1994), but little investigation of whether the expression of male traits in females is associated with such costs. The evolution of sexual size dimorphism or eventually complete loss of male traits by females in many species is indirect evidence of male traits being costly during the evolutionary past.

There is currently considerable controversy over the relative importance of different processes of speciation (Otte and Endler, 1989; Rice and Hostert, 1993; Heard and Hauser, 1994; Lambert and Spencer, 1995). Natural selection, sexual selection and random drift have been postulated to play important roles 
in the origin of species, although natural selection has the strongest empirical support, because rapid speciation is best documented in adaptive radiations. However, different mechanisms may interact (Price, 1998). Although speciation may involve both natural and sexual selection, the role of sexual selection has been emphasized by a number of studies (Darwin, 1871; Fisher, 1930; Thornhill and Alcock, 1983; Coyne, 1992; Rice and Hostert, 1993). One mechanism leading to such speciation has been presumed to be female mate preferences and male secondary sexual characters coevolving to more extreme expressions (Fisher, 1930). However, sexual selection based on female mating preferences for male viability indicators may also result in divergence and speciation (Schluter and Price, 1993). Three recent comparative studies have addressed the association between speciation and sexual selection in birds: Barraclough et al. (1995) found a larger number of species in taxa containing higher proportions of sexually dichromatic species; Mitra et al. (1996) showed a tendency towards a larger number of species in taxa with a promiscuous mating system; and Møller and Cuervo (1998) found that taxa having more species with secondary sexual characters were also more speciose. All these studies show that sexual selection is apparently a forceful power leading to rapid divergence. Our study partially supports an influence of sexual selection on speciation, since in some cases divergence of secondary sexual characters was significantly larger than that of ordinary morphological characters, presumably because secondary sexual characters are much more intensely affected by sexual selection than other traits.

In conclusion, a study of the rates of evolutionary change in birds showed in some instances that secondary sexual characters have diverged more than ordinary morphological characters among species, although that was not the general case. This result is consistent with an influence of sexual selection on morphological divergence among species. The lack of significant differences in divergence between secondary sexual characters and ordinary characters could be explained by the cost-reducing function of some ordinary morphological traits. Non-significant differences in divergence of secondary sexual characters between the sexes could be due to genetic correlations between the sexes. Tarsus length diverged more in males than in females, and sexual selection might play a role in this difference. Since the secondary sexual characters used in this study are elongated secondary sexual feathers in birds, the generality of these findings await further tests in other taxa.

\section{Acknowledgments}

We are grateful to the curators of the bird collections in Alexander Koenig Museum, Bonn, Germany, British Museum (Natural History), Tring, UK, 
Doñana Biological Station, Seville, Spain, Natural History Museum, Stockholm, Sweden, and Zoological Museum, Copenhagen, Denmark, for access to specimens. J.J.C. was supported by a post-doctoral grant from the European Union (Human Capital and Mobility Program) and by Spanish DGICYT (PB95-0110). A.P.M. was supported by an ATIPE BLANCHE from CNRS.

\section{References}

Alatalo, R.V., Höglund, J. and Lundberg, A. (1988) Patterns of variation in tail ornament size in birds. Biol. J. Linn. Soc. 34, 363-374.

Andersson, M. (1994) Sexual Selection. Princeton University Press, Princeton, NJ.

Balmford, A., Jones, I.L. and Thomas, A.L.R. (1994) How to compensate for costly sexually selected tails: the origin of sexually dimorphic wings in long-tailed birds. Evolution 48, 10621070 .

Barraclough, T.G., Harvey, P.H. and Nee, S. (1995) Sexual selection and taxonomic diversity in passerine birds. Proc. R. Soc. Lond. B 259, 211-215.

Becker, W.A. (1984) Manual of Quantitative Genetics, 4th edn. Academic Enterprises, Pullman, WA.

Brown, W.L., Jr. and Wilson, E.O. (1956) Character displacement. Syst. Zool. 5, 49-64.

Burns, K.J. (1998) A phylogenetic perspective on the evolution of sexual dichromatism in tanagers (Thraupidae): the role of female versus male plumage. Evolution 52, 1219-1224.

Chandler, C.R. (1995) Practical considerations in the use of simultaneous inference for multiple tests. Anim. Behav. 49, 524-527.

Clutton-Brock, T.H. (1985) Size, sexual dimorphism, and polygyny in primates. In W.L. Junger (ed.) Size and Scaling in Primate Biology. Plenum Press, New York, NY, pp. 51-60.

Clutton-Brock, T.H., Harvey, P.H. and Rudder, B. (1977) Sexual dimorphism, socionomic sex ratio, and body weight in primates. Nature 269, 797-799.

Clutton-Brock, T.H., Albon, S.D. and Harvey, P.H. (1980) Antlers, body size, and breeding group size in the Cervidae. Nature 285, 565-567.

Cohen, J. (1988) Statistical Power Analysis for the Behavioral Sciences, 2nd edn. Lawrence Erlbaum, Hillsdale, NJ.

Coyne, J.L. (1992) Genetics and speciation. Nature 355, 511-515.

Coyne, J.A. and Orr, H.A. (1989) Patterns of speciation in Drosophila. Evolution 43, 362-381.

Cuervo, J.J. and Møller, A.P. (1999) Phenotypic variation and fluctuating asymmetry in sexually dimorphic feather ornaments in relation to sex and mating system. Biol. J. Linn. Soc. 68, 505-529.

Cuervo, J.J. and Møller, A.P. (2000) Sex limited expression of ornamental feathers in birds. Behav. Ecol. 11 (in press).

Darwin, C. (1871) The Descent of Man, and Selection in Relation to Sex. John Murray, London, UK.

Dobzhansky, T. (1940) Speciation as a stage in evolutionary divergence. Am. Nat. 74, 312-332.

Endler, J.A. (1989) Conceptual and other problems in speciation. In D. Otte and J.A. Endler (eds) Speciation and its Consequences. Sinauer, Sunderland, MA, pp. 626-648.

Falconer, D.S. (1989) Introduction to Quantitative Genetics, 3rd edn. Longman, New York, NY.

Felsenstein, J. (1985) Phylogenies and the comparative method. Am. Nat. 125, 1-15.

Felsenstein, J. (1988) Phylogenies and quantitative methods. Ann. Rev. Ecol. Syst. 19, 445-471.

Fisher, R.A. (1930) The Genetical Theory of Natural Selection. Clarendon Press, Oxford, UK.

Garland, T., Jr. (1992) Rate tests for phenotypic evolution using phylogenetically independent contrasts. Am. Nat. 140, 509-519.

Garland, T., Jr., Harvey, P.H. and Ives, A.R. (1992) Procedures for the analysis of comparative data using phylogenetically independent contrasts. Syst. Biol. 41, 18-32. 
Garland, T., Jr., Dickerman, A.W., Janis, C.M. and Jones, J.A. (1993) Phylogenetic analysis of covariance by computer simulation. Syst. Biol. 42, 265-292.

Gingerich, P.D. (1993) Quantification and comparison of evolutionary rates. Am. J. Sci. 293-A, 453-478.

Gittleman, J.L., Anderson, C.G., Kot, M. and Luh, H.-K. (1996) Phylogenetic lability and rates of evolution: a comparison of behavioral, morphological and life history traits. In E.P. Martins (ed.) Phylogenies and the Comparative Method in Animal Behavior. Oxford University Press, New York, NY, pp. 166-205.

Grafen, A. (1989) The phylogenetic regression. Phil. Trans. R. Soc. Lond. B 326, 119-156.

Heard, S.B. and Hauser, D.L. (1994) Key evolutionary innovations and their ecological mechanisms. Hist. Biol. 10, 151-173.

Hill, G.E. (1993) Male mate choice and the evolution of female coloration in the house finch. Evolution 47, 1515-1525.

Höglund, J. (1989) Size and plumage dimorphism in lek-breeding birds: a comparative analysis. Am. Nat. 134, 72-87.

Höglund, J. and Sillén-Tullberg, B. (1994) Does lekking promote the evolution of male-biased size dimorphism in birds? On the use of comparative approaches. Am. Nat. 144, 881-889.

Irwin, R.E. (1994) The evolution of plumage dichromatism in the New World blackbirds: social selection on female brightness? Am. Nat. 144, 890-907.

Johnson, K. (1988) Sexual selection in pinyon jays. II. Male choice and female-female competition. Anim. Behav. 36, 1048-1053.

Jones, I.L. and Hunter, F.M. (1993) Mutual sexual selection in a monogamous seabird. Nature 362 , $238-239$.

Kaneshiro, K.Y. (1980) Sexual aisolation, speciation and the direction of evolution. Evolution 34, 437-444.

Kaneshiro, K.Y. and Boake, C.R.B. (1987) Sexual selection and speciation. Trends Ecol. Evol. 2 , 207-212.

Lambert, D.M. and Spencer, H.G. (eds) (1995) Speciation and the Recognition Concept. Johns Hopkins, Baltimore, MD.

Lande, R. (1980) Sexual dimorphism, sexual selection, and adaptation in polygenic characters. Evolution 34, 292-307.

Lande, R. (1981) Models of speciation by sexual selection on polygenic traits. Proc. Natl. Acad. Sci. USA 78, 3721-3725.

Lande, R. and Arnold, S.J. (1985) Evolution of mating preference and sexual dimorphism. J. Theor. Biol. 117, 651-664.

Martin, T.E. and Badyaev, A.V. (1996) Sexual dichromatism in birds: importance of nest predation and nest location for females versus males. Evolution 50, 2454-2460.

Martins, E.P. (1994) Estimating the rate of phenotypic evolution from comparative data. Am. Nat. 144, 193-209.

Martins, E.P. and Garland, T.G., Jr. (1991) Phylogenetic analyses of the correlated evolution of continuous characters: a simulation study. Evolution 45, 534-557.

Mayr, E. (1963) Animal Species and Evolution. Harvard University Press, Cambridge, MA

McLain, D.K. (1993) Copes's rules, sexual selection, and the loss of ecological plasticity. Oikos 68, 490-500.

Mitra, S., Landel, H. and Pruett-Jones, S. (1996) Species richness covaries with mating system in birds. Auk 113, 544-551.

Møller, A.P. (1994) Sexual Selection and the Barn Swallow. Oxford University Press, Oxford, UK.

Møller, A.P. (1996) The cost of secondary sexual characters and the evolution of cost-reducing traits. Ibis 138, 112-119.

Møller, A.P. and Cuervo, J.J. (1998) Speciation and feather ornamentation in birds. Evolution 52, 859-869.

Oakes, E.J. (1992) Lekking and the evolution of sexual dimorphism in birds: comparative approaches. Am. Nat. 140, 665-684.

Otte, D. and Endler, J.A. (1989) Speciation and its Consequences. Sinauer, Sunderland, MA. 
Paterson, H.E.H. (1978) More evidence against speciation by reinforcement. S. Afr. J. Sci. 74, 369-371.

Paterson, H.E.H. (1985) The recognition concept of species. In E.S. Vrba (ed.) Species and Speciation. Transvaal Museum, Pretoria, South Africa, pp. 21-29.

Pomiankowski, A. and Møller, A.P. (1995) A resolution of the lek paradox. Proc. R. Soc. Lond. B 260, 21-29.

Price, T. (1998) Sexual selection and natural selection in bird speciation. Phil. Trans. R. Soc. Lond. B 353, 251-260.

Price, T. and Birch, G.L. (1996) Repeated evolution of sexual color dimorphism in passerine birds. Auk 113, 842-848.

Purvis, A., Gittleman, J.L. and Luh, H.-K. (1994) Truth or consequences: effects of phylogenetic accuracy on two comparative methods. J. Theor. Biol. 167, 293-300.

Purvis, A. and Rambaut, A. (1995) Comparative analysis by independent contrasts (CAIC): an Apple Macintosh application for analysing comparative data. Comput. Appl. Biosci. 11, 247-251. Rice, W.R. (1989) Analyzing tables of statistical tests. Evolution 43, 223-225.

Rice, W.R. and Hostert, E.E. (1993) Laboratory experiments on speciation: What have we learned in 40 years? Evolution 47, 1637-1653.

Ryan, M.J. and Rand, A.S. (1993) Species recognition and sexual selection as a unitary problem in animal communication. Evolution 47, 647-657.

Schluter, D. and Price, T. (1993) Honesty, perception and population divergence in sexually selected traits. Proc. R. Soc. Lond. B 253, 117-122.

Selander, R.K. (1966) Sexual dimorphism and differential niche utilization in birds. Condor 68 , $113-151$.

Sheldon, F.H. and Winkler, D.W. (1993) Intergeneric phylogenetic relationships of swallows estimated by DNA-DNA hybridization. Auk 110, 798-824.

Sibley, C.G. and Ahlquist, J.E. (1990) Phylogeny and Classification of Birds. Yale University Press, New Haven, CT.

Sokal, R.R. and Rohlf, F.J. (1995) Biometry, 3rd edn. Freeman, San Francisco, CA.

Svensson, L. (1984) Identification Guide to European Passerines, 2nd edn. L. Svensson, Stockholm, Sweden.

Templeton, A.R. (1981) Mechanisms of speciation - a population genetic approach. Annu. Rev. Ecol. Syst. 12, 23-48.

Templeton, A.R. (1989) The meaning of species and speciation. In D. Otte and J.A. Endler (eds) Speciation and its consequences. Sinauer, Sunderland, MA, pp. 3-27.

Thornhill, R. and Alcock, J. (1983) The Evolution of Insect Mating Systems. Harvard University Press, Cambridge, MA.

West-Eberhard, M.J. (1983) Sexual selection, social competition, and speciation. Q. Rev. Biol. 58, $155-183$.

West-Eberhard, M.J. (1984) Sexual selection, competitive communication and species-specific signals in insects. In T. Lewis (ed.) Insect communication. Academic Press, New York, NY, pp. 283-324.

Wright, S.P. (1992) Adjusted p-values and simultaneous inference. Biometrics 48, 1005-1013. 